\title{
Hypohidrotic ectodermal dysplasia, central nervous system malformation, and distinct facial features: confirmation of a distinct entity?
}

\author{
Dominique Soekarman, Jean Pierre Fryns
}

\begin{abstract}
Internal hydrocephalus with partial hypoplasia of the cerebellum was observed in a severely mentally retarded boy who showed signs of ectodermal dysplasia. Diagnostic considerations are discussed. Reports of the triad mental retardationCNS malformation-ectodermal dysplasia are rare. In 1989 we reported a case with these signs that shows a striking facial similarity to the case presented here. (f Med Genet 1993;30:245-7)
\end{abstract}

The diagnosis of ectodermal dysplasia syndrome requires involvement from birth of hair, skin, teeth, or nails without progression of the condition. ${ }^{12}$ Diagnosis is often difficult since any ectodermal derivative may be involved in varying degrees. To circumvent this problem, Freire-Maia and Pinheiro ${ }^{2}$ designed a classification system which contains over 100 different, clinically distinct conditions. However, assignment of any particular case to a specific subtype in this classification system may still be difficult. We present a case of a severely mentally retarded boy with a medical history and abnormalities of ectodermal derivatives suggesting the diagnosis 'subtype of ectodermal dysplasia'.

\section{Case report}

The patient was the first born son of young, non-consanguineous parents. A brother of the mother has Down's syndrome (probably age related) and her nephew has spina bifida. The remaining family history is negative for other congenital malformations or hereditary conditions. The mother of the patient has fine, sparse, fair hair but has an otherwise normal phenotype.

The pregnancy was complicated by premature contractions and hydramnios. A dysmature boy was born after 37 weeks of gestation. Measurements at birth were weight $2530 \mathrm{~g}$, length $46 \mathrm{~cm}$, and head circumference $33 \mathrm{~cm}$. Feeding was difficult, requiring administration by a nasogastric tube, and parameters for weight and length persisted on the 3rd centile while the head circumference stayed on the 10th centile. Clinical examination at 7 months showed a large, open anterior fontanelle, micrognathia, and a cleft palate. He suffered from dacryocystitis of his right eye owing to an imperforate lacrimal duct. He had no hair until 8 months. Neurological examination showed axial hypotonia combined with hypertonic lower extremities. His second toes overlapped the first.

A CT scan showed dilatation of the third, fourth, and lateral ventricles which remained stationary in time without signs of hypertension. Also partial hypoplasia of the cerebellum was observed.

At 13 months of age developmental retardation was obvious. Parameters for weight and length were still below the $3 \mathrm{rd}$ centile $(6.56 \mathrm{~kg}$ and $68.5 \mathrm{~cm}$ respectively) while head circumference was on the 10th centile. Admission to hospital was necessary as his condition worsened because of feeding problems, an upper respiratory tract infection, and recurrence of dacryocystits of his right eye. At 16 months his cleft palate was surgically corrected. However, no remarkable change in the feeding problems (especially for solid food) occurred.

At $3 \frac{1}{2}$ years old, he was admitted to hospital for a respiratory infection with febrile convulsions and head banging. Since febrile convulsions had occurred for the second time that year, anti-epileptic drugs were given. Weight was $10.40 \mathrm{~kg}$ (less than the $3 \mathrm{rd}$ centile), length was $95 \mathrm{~cm}$ (less than the 25 th centile), and head circumference was $50 \mathrm{~cm}$ (25th to 50 th centile). This ratio persisted during the following years.

Clinical observations at that time (figs 1 and 2) were similar to the present. $\mathrm{He}$ is now 8 years old and an anxious, pale, and thin child. $\mathrm{He}$ is severely mentally retarded. Since the birth of a healthy sister when he was 5 years old he developed serious behavioural problems with anxiety and aggression. The scalp veins are visible and dilated. His hair is fair, curly, and fine. Microscopic examination shows irregular and missing cuticles. Serum copper and caeruloplasmin levels are normal. He shows frontal bossing, hypoplasia of the maxilla, hypertelorism, and ectropion of the right lower eyelid. He has a protruding tongue. Both ears are low set, but hearing is adequate. He has diastema between his upper incisors, and one conical and one peg shaped incisor in the 


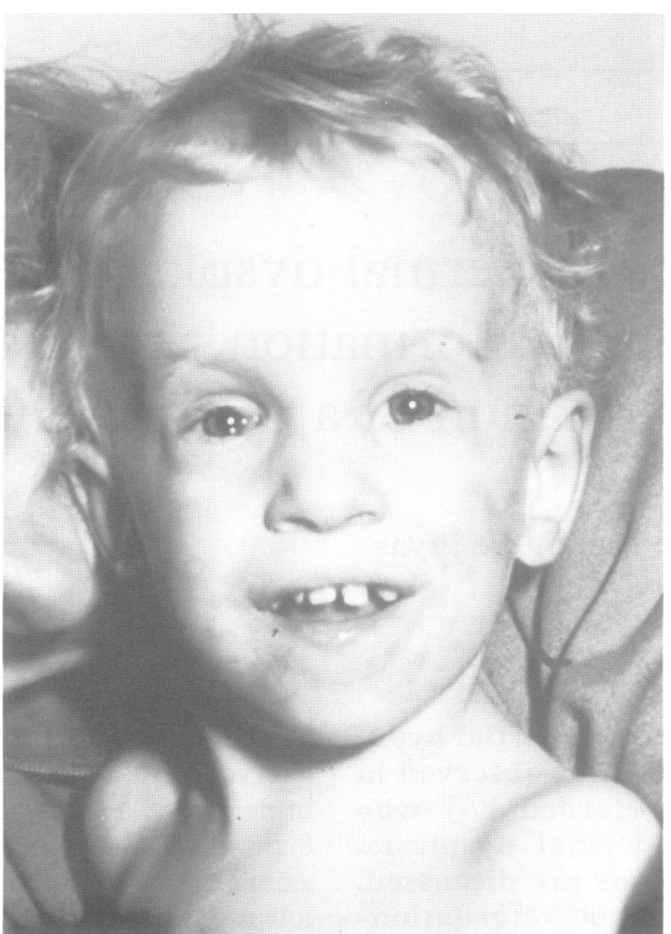

Figure 1 Facies of the patient.

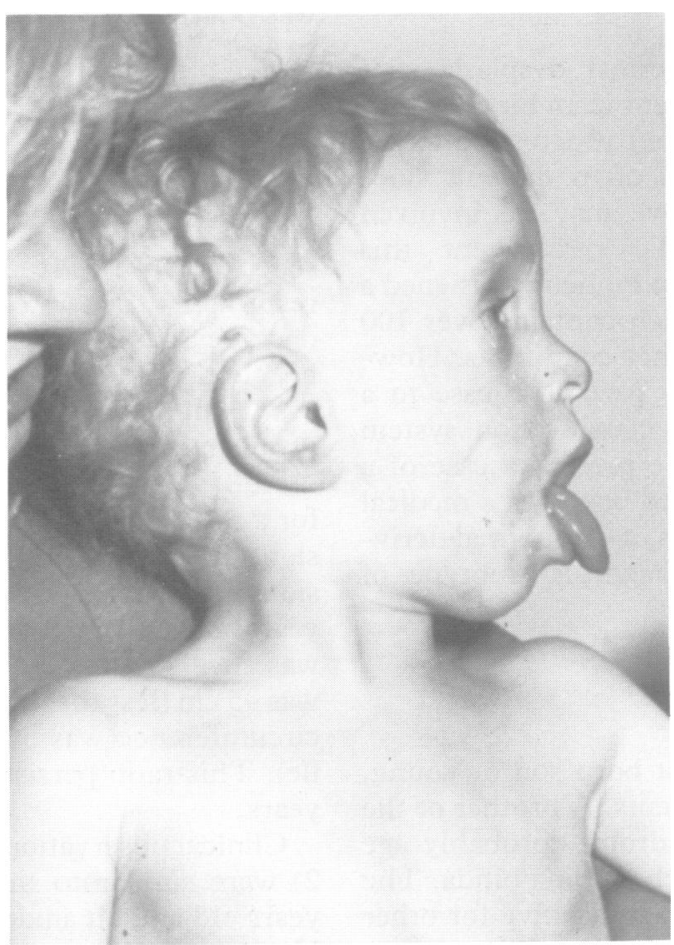

Figure 2 Profile of the patient.

lower jaw (figs 1 and 3). The lateral incisors in both upper and lower jaws are missing. His skin is thin with little subcutaneous fat, but a biopsy showed normal skin structures. He has small nipples. Sweating seems minimal. A sweat test was performed at the age of 2 years: $139.76 \mathrm{mg}$ sweat was produced with a chloride content of $4.12 \mathrm{mEq} / 1$ (normal range). His nails are short and broad. His penis is small and a partially undescended testis can be felt

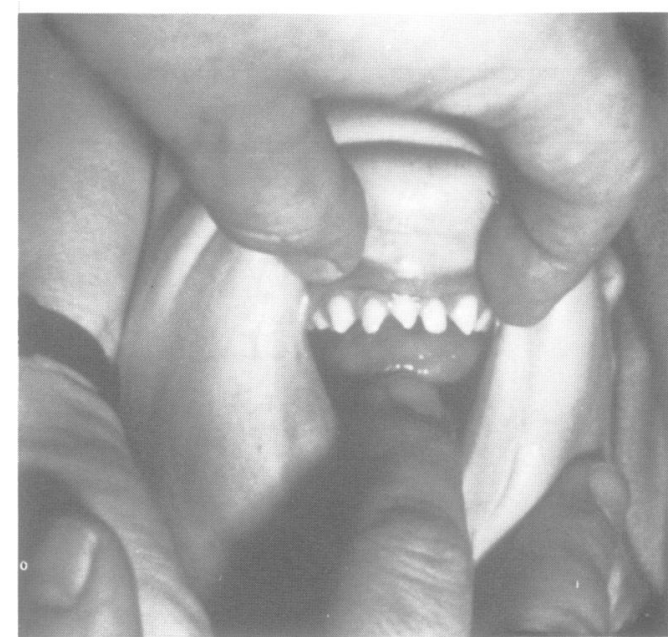

Figure 3 Teeth in lower jaw of the patient.

on the right. There is a broad gap between his first and second toes and the third toes are hammer toes. He walks on tiptoe with a broad based gait. Bilateral calcaneovalgus was seen on radiological examination. The karyotypes of both parents and child are normal.

\section{Discussion}

In summary, the child was born with a PierreRobin sequence and feeding problems were present from birth onwards. He suffered from recurring respiratory tract and eye infections. He combines a specific facies with severe mental retardation and a CNS malformation.

This case presents with many signs pointing to the diagnosis of a subtype of ectodermal dysplasia, maybe ' $\mathrm{X}$ linked hypohidrotic ectodermal dysplasia'. In favour of this diagnosis are: (1) the subtle signs in the mother (fair, fine, sparse hair), (2) a history of feeding problems, failure to thrive with parameters for weight and length persisting below the population mean, recurrent infections, and febrile convulsions, and (3) the condition of the hair, skin, and teeth. ${ }^{3}$ The variant of hypohidrotic ectodermal dysplasia which is inherited in an autosomal recessive mode is clinically indistinguishable and might be another option since signs in the mother are minimal. Some authors even question whether these two types of hypohidrotic ectodermal dysplasia really exist and imply that in fact only one such condition exists, inherited in an $\mathrm{X}$ linked mode. ${ }^{4}$ An important diagnostic sign in hypohidrotic ectodermal dysplasia is impaired sweating. Clinical examination of our patient repeatedly showed a dry skin with minimal sweating. However, sweat production was present as shown by a sweat test in which $139.76 \mathrm{mg}$ sweat was collected. Berg et $a l^{5}$ reviewed all cases of ectodermal dysplasia reported so far for methods used to estimate objectively sweat production. They concluded that no standardised sweat test had been used in these cases and advocated an accurate evaluation of sweating in ectodermal dysplasia syndromes. However, the methods they recommend for objective testing of sweat production (such as visualisation by dyes or counting of sweat 
pores) require cooperation from the patient. Unfortunately, these tests can not be used in our case without general anaesthesia since he is a severely retarded child who is extremely sensitive to any unfamiliar situation and who is easily frightened. For the same reason it was impossible to make dental $x$ rays for further investigation of the boy's teeth. Although the clinical findings in this case might be compatible with the diagnosis of hypohidrotic ectodermal dysplasia, the patient shows additional abnormalities which are uncommon in this condition.

Cleft palate has been described in other subtypes of ectodermal dysplasia, for example, Rapp-Hodgkin ectodermal dysplasia (ED), ectrodactyly-ectodermal dysplasia-clefting (EEC) syndrome, and other conditions which combine facial clefts with abnormalities of ectodermal derivatives. $^{6-10}$ All these show a phenotype and clinical findings which clearly differ from the case we present.

Lacrimal duct anomalies are found in the EEC syndrome as well as facial clefts, dental dysplasia, short stature, fair skin and hair, and hypoplastic nipples. However, the boy's facies and mental retardation and the absence of abnormalities of his extremities argue against this diagnosis.

Although mental retardation has been documented in various subtypes of ectodermal dysplasia, its real incidence per subgroup is not firmly established so far. ${ }^{11} 12$ However, it seems not to be a feature of $\mathrm{X}$ linked hypohidrotic ED (the largest subgroup investigated for this feature so far).${ }^{13}$ Some authors suggest that the febrile convulsions seen in this condition might be responsible if mental retardation is found in this subtype of ectodermal dysplasia. ${ }^{14}$

Both short stature and retarded mental development are often found in rare subtypes of ED. Such cases are associated with other malformations and more severe forms of hypotrichosis, hypodontia, and skin or nail abnormalities in contrast to our case. ${ }^{15-18}$

Of specific interest is the CNS malformation found in our case. Although the central nervous system originates from the embryological ectoderm, reports of investigations of the CNS in conditions with signs of ectodermal dysplasia are rare. ${ }^{19}$ Moreover, comparison of such reports with our case shows little similarity in phenotype and clinical characteristics. ${ }^{2}$ For example, Cortes and Lacassie ${ }^{20}$ reported a boy with hypoplastic nails, malformed hands and feet, curly hair, small lower teeth, and seizures. A CT scan showed 'asymmetry of the cerebral hemispheres' without further specifications. Rushton and Genel ${ }^{21}$ described a brother and sister with mental retardation, short stature, hypodontia, and abnormalities of the neurological and endocrine system. A CT scan showed cerebellar atrophy.

Only one previously reported case shows a striking similarity of the facies and of clinical characteristics to the patient presented here. ${ }^{22}$ In this case report we described a severely mentally retarded boy with hypohidrotic ectodermal dysplasia, primary hypothyroidism, and agenesis of the corpus callosum. Enlarged lateral ventricles were also visible on the CT scan. His history was also complicated by swallowing difficulties and frequent respiratory tract and eye infections. ${ }^{22}$

We believe that both boys might suffer from the same genetic condition which combines mental retardation with signs of ectodermal dysplasia and CNS malformations. However, more reports of similar cases are necessary to confirm this. Our observations indicate that any patient who shows signs of ectodermal dysplasia with mental retardation or seizures should be investigated further for CNS malformations.

1 Solomon LM, Cook B, Klipfel W. The ectodermal dysplasias. Dermatol Clin 1987;5:231-7.

2 Freire-Maia N, Pinheiro M. Ectodermal dysplasias: a clinical and genetic study. New York: Alan R Liss, 1984.

3 Clarke A, Phillips DiM, Brown R, Harper PS. Clinical aspects of $\mathrm{X}$-linked hypohydrotic ectodermal dysplasia. Arch Dis Child 1987;62:989-96.

4 Sybert VP. Hypohidrotic ectodermal dysplasia: argument against an autosomal recessive form clinically indistinguishable from X-linked hypohidrotic ectodermal dysplasia (Christ-Siemens-Touraine syndrome). Pediatr plasia (Christ-Siemens-

5 Berg D, Weingold DH, Abson KG, Olsen EA. Sweating in ectodermal dysplasia syndromes. Arch Dermato 1990;126:1075-9.

6 Breslau-Siderius EJ, Lavrijsen APM, Otten FWA, van der Schroeff JG, Swart JGN. The Rapp-Hodgkin syndrome Am $\mathcal{F}$ Med Genet 1991;38:107-10

7 Rodini ESO, Richieri-Costa A. EEC syndrome: report on 20 new patients, clinical and genetic considerations. $A m \mathcal{F}$
Med Genet 1990;37:42-53.

8 Martinez BR, Monasterio LA, Pinheiro M, Freire-Maia N. Cleft lip-palate-oligodontia-syndactyly-hair alterations, a new syndrome. Review of the conditions combining ectodermal dysplasia and cleft lip/palate. Am $\mathcal{F}$ Med Genet

9 Greene SL, Michels VV, Doyle JA. Variable expression in ankyloblepharon-ectodermal defects-cleft lip and palate

syndrome. Am $\mathcal{F}$ Med Genet 1987;27:207-12.
10 Rodini ESO, Richieri-Costa A. Autosomal recessive ectodermal dysplasia, cleft lip/palate, mental retardation, and syndactyly: the Zlotogora-Ogur syndrome. $\mathrm{Am} \mathcal{f} \mathrm{Med}$ Genet 1990;36:473-6.

11 Tanner BA. Intellectual functioning and ectodermal dysplasia. Pediatrics 1985;75:126.

12 Hoyme HE. Reply to Tanner's letter. Pediatrics 1985;75:126-7.

13 Clarke A. Hypohidrotic ectodermal dysplasia. 7 Med Gene 1987;24:659-63.

14 Halperin SL, Curtis GM. Anhidrotic ectodermal dysplasia associated with mental deficiency. Am $\mathcal{F}$ Ment Defic 1942;46:459-63.

15 Blau EB. Ectodermal dysplasia, osteosclerosis, atrial septal defect, malabsorption, neutropenia, growth, and mental retardation: the Côté-Katsantoni syndrome? $\mathrm{Am} \mathcal{F ~ M e d}$

Genet 1987;26:729-32.
16 Jackson CE, Weiss L, Watson JHL. 'Brittle' hair with short stature, intellectual impairment and decreased fertility: an autosomal recessive syndrome in an Amish kindred. Pediatrics 1974;54:201-7.

17 Schinzel A. A case of multiple skeletal anomalies, ectodermal dysplasia, and severe growth and mental retardation. Helv Paediatr Acta 1980;35:243-51.

18 Pinheiro M, Freire-Maia N, Chautard-Freire-Maia EA, Araujo LMB, Liberman B. AREDYLD. A syndrome combining an acrorenal field defect, ectodermal dysplasia lipoatrophic diabetes, and other manifestations. $A m \mathcal{F}$ Med Genet 1983;16:29-33.

19 Cordova MA, Truong D, Blackburn JG. Preliminary neurologic and neurophysiologic findings in ectodermal dysplasias. Birth Defects 1988;24:65-71.

20 Cortes F, Lacassie Y. An unusual case of ectodermal dysplasia. Am $\mathcal{Y}$ Med Genet 1986;25:289-91.

21 Rushton AR, Genel M. Hereditary ectodermal dysplasia, olivopontocerebellar degeneration, short stature, and

22 Fryns JP, Chrzanowska J, van den Berghe $\mathrm{H}$. Hypohidrotic ectodermal dysplasia, primary hypothyroidism, and agenesis of the corpus callosum. $\mathcal{F}$ Med Genet 1989;26:520-1. 